\title{
Effect of Thickness on Crystal Structure and Dispersion Parameters of Haematite Iron Oxide by Spray Pyrolysis Technique
}

\author{
Ahmed T. HASsAN ${ }^{a}$ AND EHSSAN S. HASSAN ${ }^{b, *}$ \\ ${ }^{a}$ Ministry of Education, Directorate General for Education, Iraq, Baghdad \\ ${ }^{b}$ Department of Physics, College of Science, Mustansiriyah University, Baghdad, Iraq \\ Doi: 10.12693/APhysPolA.140.295 *e-mail: ehsanphysicyan@uomustansiriyah.edu.iq
}

\begin{abstract}
Thin films of haematite iron oxide $\mathrm{Fe}_{2} \mathrm{O}_{3}$ (of thicknesses $t=200,300$, and $400 \mathrm{~nm}$ ) were prepared on glass substrates using a spray pyrolysis technique. X-ray diffraction measurements showed that the films were polycrystalline, with crystallite size increasing from 16.8 to $30.7 \mathrm{~nm}$ as the sample thickness increased. The refractive index data was used to calculate the single oscillator power and scattering energy as predicted by the Wemple-Domenico model. The dispersion energy increased from 10.86 to $16.54 \mathrm{eV}$ as the thickness increased. The optical energy gap decreased from 2.74 to $2.21 \mathrm{eV}$. The calculated values for the Urbach energy were found to increase from 680 to $1230 \mathrm{meV}$ as the thickness increased.
\end{abstract}

topics: Urbach energy, transmittance, absorption coefficient

\section{Introduction}

Haematite iron oxide $\left(\mathrm{Fe}_{2} \mathrm{O}_{3}\right)$ has an average direct optical energy gap $E_{\mathrm{g}}=2 \mathrm{eV}$. Al-Kuhaili et al. [1] showed that $\alpha-\mathrm{Fe}_{2} \mathrm{O}_{3}$ films exhibit the presence of both direct and indirect band gaps. The direct band gap had a value of $2.18 \mathrm{eV}$ for both types of films investigated. The energy of the indirect band gap was $1.82 \mathrm{eV}$ for the films deposited on unheated substrates and $1.96 \mathrm{eV}$ for the films deposited on heated substrates [1]. Thin films are low in cost, stable in aqueous solution, and non-toxic. Thin films can be used in gas sensors $[2,3]$ due to their high sensitivity to combustible gases, and as radiation filters in the visible region of the electromagnetic spectrum. The $\mathrm{Fe}_{2} \mathrm{O}_{3}$ thin films have been produced using methods such as pulsed laser deposition, atomic layer deposition [4], spray pyrolysis technique (SPT), RF magnetron sputtering, and the sol-gel method [5, 6]. The model suggested by Wemple and DiDomenico to describe the dispersion of the refractive index of solids is further developed in terms of the cation local bonding environment and its effect on the value of the dispersion energy. In this work, SPT was adopted to deposit $\mathrm{Fe}_{2} \mathrm{O}_{3}$ thin films.

The objective of this study is to assess the effect of film thickness on the dispersion parameter of $\mathrm{Fe}_{2} \mathrm{O}_{3}$ thin films deposited by SPT. The process of calculating the optical energy gap, the Urbach energy, the dispersion energy, and the refractive index from the transmittance values will be of interest to researchers.

\section{Materials and methods}

Spray pyrolysis was undertaken using a standard laboratory glass spray bottle with a yield needle with a span of $1 \mathrm{~mm}$. The volume of the solvent used for deposition was $100 \mathrm{ml}$. The preliminary solution was sprayed onto a preheated square glass plate of $25.5 \mathrm{~mm}$ dimensions and $0.7 \mathrm{~mm}$ thickness using compressed air. The solvent flow rate was $8 \mathrm{ml} / \mathrm{min}$ and the distance from the needle to the substrate was $30 \mathrm{~cm}$. The technique involves spraying cycles of $5 \mathrm{~s}$ followed by a $1 \mathrm{~min}$ pause, to avoid sudden cooling of the substrate. The substrates were installed on red of a heater and their temperature was controlled with a thermocouple (chromel-alumel) to keep them at an optimized temperature of $450^{\circ} \mathrm{C}$. Hydrated haematite chloride $\left(\mathrm{FeCl}_{3} \cdot 6 \mathrm{H}_{2} \mathrm{O}\right)$ of $162.21 \mathrm{~g} / \mathrm{mol}$ molecular weight was used for the preparation of the $\mathrm{Fe}_{2} \mathrm{O}_{3}$ thin films. The solution was prepared at room temperature with concentration of $0.1 \mathrm{M}$ by dissolving $1.6221 \mathrm{~g}$ of $\mathrm{FeCl}_{3} \cdot 6 \mathrm{H}_{2} \mathrm{O}$ in $100 \mathrm{ml}$ of distilled water. To ensure full solubility a magnetic stirrer was used. After deposition, the films were allowed to cool slowly to ambient temperature. Thickness measurements for the as-deposited thin films were carried out by weighing. The structural properties were measured with X-ray diffraction (XRD, Shimadzu XRD-6000, using $\mathrm{Cu} K_{\alpha}$ radiation of a wavelength of $1.5406 \AA$ ) and a UV/visible scanning spectrophotometer (Shimadzu UV-1800) was used to record the absorbance spectra in the wavelength range of $300-900 \mathrm{~nm}$. 


\section{Results and discussion}

Figure 1a presents the X-ray diffraction patterns of $\mathrm{Fe}_{2} \mathrm{O}_{3}$ deposited by SPT on glass substrates at different thicknesses $t$, i.e., 200, 300, and $400 \mathrm{~nm}$. The diffraction patterns in Fig. 1 show that the films are polycrystalline. We observed also that the highest reflection intensity in all layers stems from the (220) plane at an angle $2 \theta=30.121^{\circ}$ and that the full width at half maximum (FWHM) decreases with increasing film thickness. The latter indicates an increase in crystallite size from $16.89 \mathrm{~nm}$ to $30.78 \mathrm{~nm}$ as the sample thickness increases from $200 \mathrm{~nm}$ to $400 \mathrm{~nm}$, as shown in Fig. 1b. Also, secondary (331), (421), and (521) reflexes at $2 \theta=$ $38.121^{\circ}, 2 \theta=38.121^{\circ}$, and $2 \theta=38.121^{\circ}$, respectively, are observed. All positions agree with those of the international card JCPDS (Card No. 39-1346).

Table I shows the structural parameters of $\mathrm{Fe}_{2} \mathrm{O}_{3}$ thin films prepared by SPT. The crystallite size $D[\mathrm{~nm}]$ is calculated using $[7,8]$

$$
D=\frac{K \lambda}{\beta \cos (\theta)},
$$

where $K$ is a dimensionless shape factor, $\lambda$ is the $\mathrm{X}$-ray wavelength $(1.54178 \AA), \beta$ is the line width at half the maximum intensity, and $\theta$ is the Bragg angle. The lattice parameters, in turn, are calculated using $[7,8]$

$$
\frac{1}{d_{h k l}}=\frac{h^{2}}{a^{2}}+\frac{k^{2}}{b^{2}}+\frac{l^{2}}{c^{2}},
$$

where $h, k$, and $l$ are the Miller indices, $a, b$, and $c$ are the lattice parameters, and $d_{h k l}$ is the interplanar distance.

Figure 2 presents the transmittance spectra of the samples prepared with different thicknesses $(t=200,300$, and $400 \mathrm{~nm})$ deposited on glass substrates using SPT. Transmittance increases with wavelength growth. This increase is due to the fact that the cross-section area of the dispersed incident rays reduces $[9,10]$.
The value of the absorption coefficient $\alpha$ can be calculated with

$$
\alpha=\frac{2.303 A}{t},
$$

where $A$ is the absorbance and $t$ is the film thickness. It is seen in Fig. 2, that both quantities, $t$ and $T$, are depended in our system on the considered wavelength. Thus, there is a non-trivial relation between the transmittance and absorbance. It is indicated in further results in this paper.
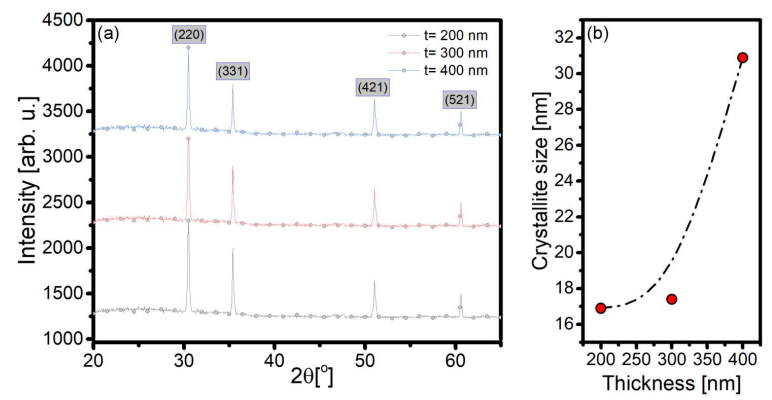

Fig. 1. (a) X-ray diffraction pattern and (b) crystallite size for $\mathrm{Fe}_{2} \mathrm{O}_{3}$ deposited on glass substrate by SPT.

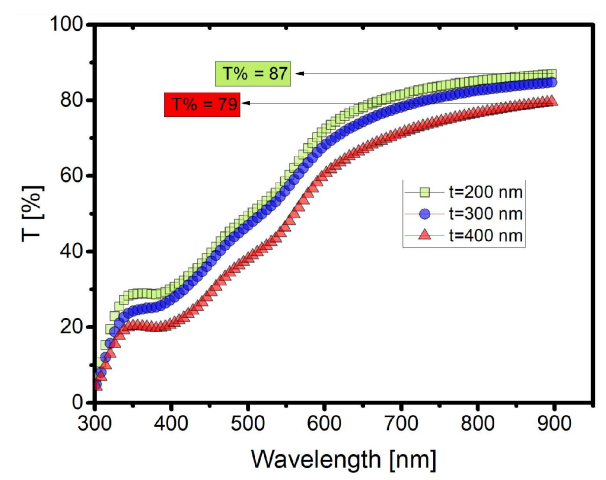

Fig. 2. Transmittance spectrum of $\mathrm{Fe}_{2} \mathrm{O}_{3}$ deposited on glass substrates by SPT.

\begin{tabular}{|c|c|c|c|c|c|c|c|}
\hline \multirow{2}{*}{$\begin{array}{c}\text { Thickness } \\
\text { [nm] }\end{array}$} & \multirow{2}{*}{$\begin{array}{l}(h k l) \\
\text { plane }\end{array}$} & \multirow{2}{*}{$\begin{array}{c}\text { FWHM } \\
\text { [deg] }\end{array}$} & \multicolumn{2}{|c|}{$2 \theta$} & \multirow{2}{*}{$\begin{array}{l}\mathrm{XRD} \\
d[\AA]\end{array}$} & \multirow{2}{*}{$\begin{array}{l}\text { Crystallite } \\
\text { size } D[\mathrm{~nm}]\end{array}$} & \multirow{2}{*}{$\begin{array}{c}\text { Lattice } \\
\text { parameter }[\mathrm{nm}]\end{array}$} \\
\hline & & & XRD & ASTM & & & \\
\hline \multirow{4}{*}{200} & $(220)$ & 0.374 & 30.12 & 30.241 & 0.208 & 16.89 & 0.4174 \\
\hline & $(311)$ & & 35.92 & 35.630 & & & \\
\hline & $(421)$ & & 50.23 & 50.007 & & & \\
\hline & $(521)$ & & 59.56 & 60.685 & & & \\
\hline \multirow{4}{*}{300} & $(220)$ & 0.350 & 30.23 & 30.241 & 0.210 & 17.39 & 0.4204 \\
\hline & $(331)$ & & 35.57 & 35.630 & & & \\
\hline & $(421)$ & & 50.81 & 50.007 & & & \\
\hline & $(521)$ & & 59.92 & 60.685 & & & \\
\hline \multirow{4}{*}{400} & $(220)$ & 0.342 & 30.38 & 30.241 & 0.208 & 30.88 & 0.4170 \\
\hline & $(331)$ & & 35.73 & 35.630 & & & \\
\hline & $(421)$ & & 50.16 & 50.007 & & & \\
\hline & $(521)$ & & 59.99 & 60.685 & & & \\
\hline
\end{tabular}

Structural parameters of $\mathrm{Fe}_{2} \mathrm{O}_{3}$ thin films prepared by SPT technique.

TABLE I 
The optical variables of $\mathrm{Fe}_{2} \mathrm{O}_{3}$ thin films.

\begin{tabular}{c|c|c|c|c|c|c|c|c|c|c}
\hline \hline Thickness $[\mathrm{nm}]$ & $E_{\mathrm{g}}^{\mathrm{opt}}[\mathrm{eV}]$ & $E_{\mathrm{o}}[\mathrm{eV}]$ & $E_{\mathrm{d}}[\mathrm{eV}]$ & $E_{\mathrm{U}}[\mathrm{meV}]$ & $\varepsilon_{0}$ & $n_{0}$ & $M_{-1}$ & $M_{-3}\left[\mathrm{eV}^{-2}\right]$ & $S_{\mathrm{o}}\left[\times 10^{-3} \mathrm{~m}^{-2}\right]$ & $\lambda_{\mathrm{o}}[\mathrm{nm}]$ \\
\hline 200 & 2.74 & 2.22 & 10.86 & 680 & 5.89 & 2.42 & 4.89 & 0.99 & 2.21 & 534 \\
300 & 2.48 & 2.16 & 13.89 & 790 & 7.43 & 2.73 & 6.43 & 1.37 & 3.71 & 512 \\
400 & 2.21 & 2.21 & 16.54 & 1230 & 8.48 & 2.91 & 7.48 & 1.53 & 3.95 & 526
\end{tabular}
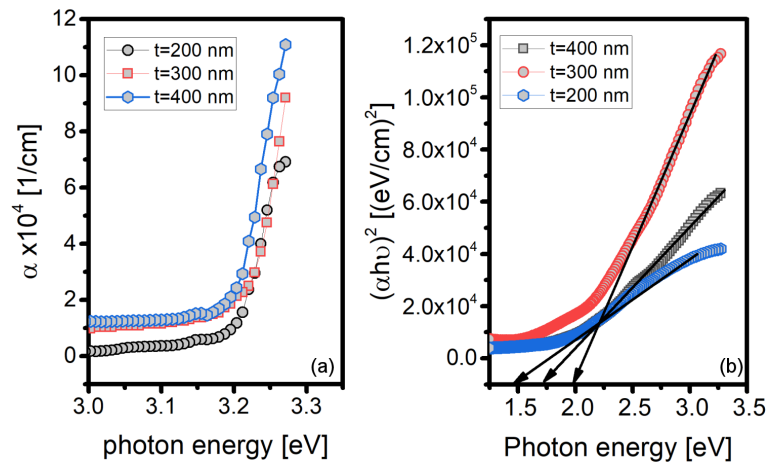

Fig. 3. Absorption coefficient $\alpha$ (a) and $(\alpha h \nu)^{2}(\mathrm{~b})$ as a function of photon energy $h \nu$ of $\mathrm{Fe}_{2} \mathrm{O}_{3}$ deposited by SPT.

The absorption coefficient $\alpha$ increases with the photon energy, as shown in Fig. 3a.

The relation between the absorption coefficient and the photon energy is given by the Tauc equation

$$
\alpha h \nu=B\left(h \nu-E_{\mathrm{g}}^{\mathrm{opt}}\right)^{n},
$$

where $B$ is a constant, $E_{\mathrm{g}}^{\mathrm{opt}}$ is the optical band gap energy, $h \nu$ is the photon energy, $\alpha$ reads as $\alpha(\nu)$, and $n$ is an index that depends on the kind of transition (direct or indirect). In the case a of direct transition the appropriate index is $n=1 / 2$. The optical band gap energy can be determined from the dependence of $(\alpha h \nu)^{2}$ vs $h \nu$ by linear extrapolation of the curves towards the $(\alpha h \nu)^{2}=0$ axis.

Figure $3 \mathrm{~b}$ shows the variation in the optical energy gap for different thicknesses values. The reduction in straight band gap as thickness increases can be attributed to an increase in crystallization as well as an increase in crystallite (grain) size. Absorption near the edge of the basic absorption coefficient is largely dependent on the energy of the photons, the Urbach energy enters through the following relationship [11]

$$
\alpha=\alpha_{0} \exp \left(\frac{h \nu}{E_{\mathrm{U}}}\right) .
$$

Taking the natural logarithm of (5), one gets

$$
\ln (\alpha)=\ln \left(\alpha_{0}\right)+\left(\frac{h \nu}{E_{\mathrm{U}}}\right)
$$

where $\alpha_{0}$ is constant, and $E_{\mathrm{U}}$ is the Urbach energy. The linear relation between $\ln (\alpha)$ and the photon energy is expected. In Fig. 4, we can determine the Urbach energy for it is equal to the inverse of the slope of the straight line. The obtained $E_{\mathrm{U}}$ values are shown in Table II. The Urbach energy levels

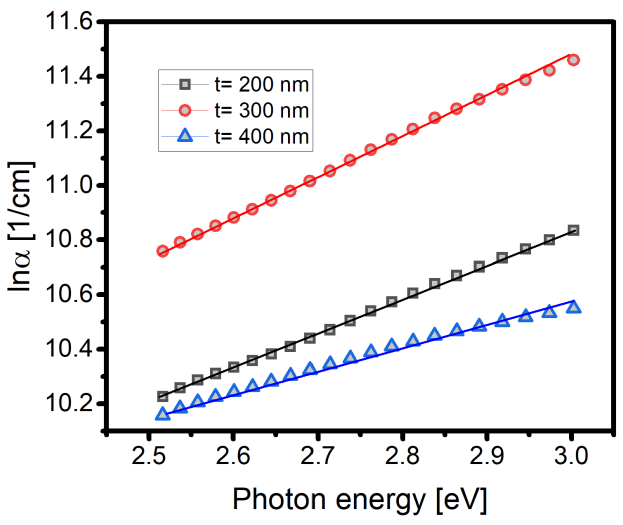

Fig. 4. The logarithm $\ln (\alpha)$ as a function of energy $h \nu$ calculated for $\mathrm{Fe}_{2} \mathrm{O}_{3}$.

increase with the thickness of the films. The increase in $E_{\mathrm{U}}$ is credited to the increase in mass as the films increase in thickness. The dispersal of refractive index of $\mathrm{Fe}_{2} \mathrm{O}_{3}$ films, modelled by the single oscillator, is articulated by Wemple and DiDomenico [12]. The refractive index has been examined in the interband absorption boundary [13]

$$
n^{2}=1+\frac{E_{\mathrm{d}} E_{\mathrm{o}}}{E_{\mathrm{o}}^{2}-(h \nu)^{2}} .
$$

Now, one can rewrite (7) as follows

$$
\left(n^{2}-1\right)^{-1}=\frac{E_{\mathrm{o}}}{E_{\mathrm{d}}}-\frac{(h \nu)^{2}}{E_{\mathrm{d}} E_{\mathrm{o}}},
$$

where $E_{\mathrm{o}}$ is the typical oscillator energy (typical of the visual band gap) and $E_{\mathrm{d}}$ is the dispersal energy factor of the objects [14]. The dependence $\left(n^{2}-1\right)^{-1}$ against $(h \nu)^{2}$, shown in Fig. 5 , allows to determine the oscillator constant when assigning a linear role to the ratio of $E_{\mathrm{o}}$ and $E_{\mathrm{d}}$, i.e., $E_{\mathrm{o}} / E_{d}$. The values of the parameter $E_{\mathrm{o}} / E_{\mathrm{d}}$ and the slope $1 /\left(E_{\mathrm{o}} E_{\mathrm{d}}\right)$ that describe the dependence of single effective oscillator parameters on thickness, are shown in Table I. The static refractive index $n_{0}$ is evaluated as follows $n_{0}^{2}=n^{2}(h \nu=0)=1+\frac{E_{\mathrm{d}}}{E_{\mathrm{o}}}$, and the infinite wavelength dielectric constant is given by $\varepsilon_{0}=n_{0}^{2}$. The obtained values are shown in Table II.

The moments of visual dispersal spectra, $M_{-1}$ and $M_{-3}$, can be evaluated as [15]

$$
E=\frac{M_{-1}}{M_{-3}} \quad \text { and } \quad E_{\mathrm{d}}^{2}=\frac{M_{-1}^{3}}{M_{-3}} .
$$

When rearranging (9), one gets

$$
M_{-1}=\frac{E_{\mathrm{d}}}{E_{\mathrm{o}}} \quad \text { and } \quad M_{-3}=\frac{M_{-1}}{E_{\mathrm{o}}^{2}} .
$$




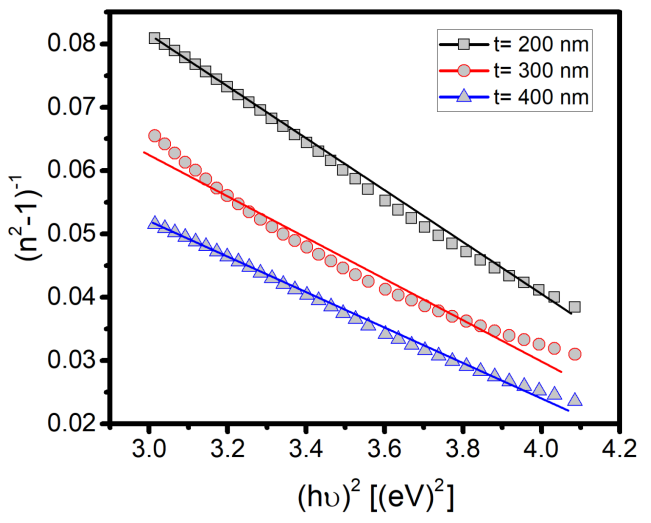

Fig. 5. Plot of $\left(n^{2}-1\right)^{-1}$ as a function of $(h \nu)^{2}$ for $\mathrm{Fe}_{2} \mathrm{O}_{3}$.

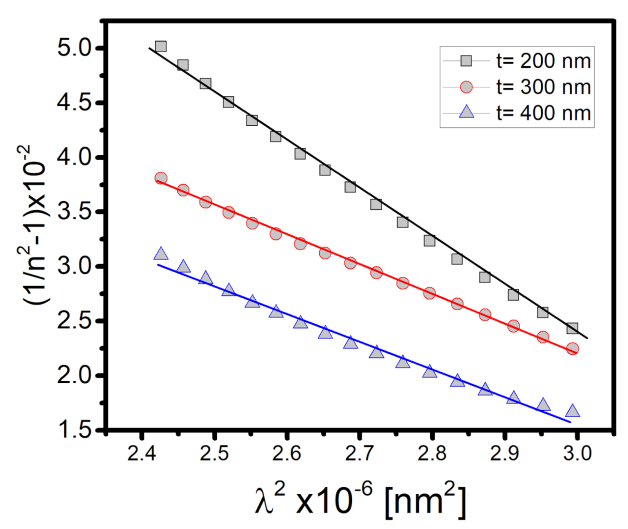

Fig. 6. Dependence of $\left(n^{2}-1\right)^{-1}$ on $\lambda^{2}$ for $\mathrm{Fe}_{2} \mathrm{O}_{3}$.

The obtained $M_{-1}$ and $M_{-3}$ moments replace the thickness. The estimated values of $M_{-1}$ range from 4.89 to 7.48 [dimensionless], and $M_{-3}$ lies between 0.99 and $1.53 \mathrm{eV}^{-2}$, as shown in Table I. The singleterm Sellmeier relationship is given as

$$
n^{2}-1=\frac{S_{\mathrm{o}} \lambda_{\mathrm{o}}^{2}}{1-\left(\frac{\lambda_{\mathrm{o}}}{\lambda}\right)^{2}} .
$$

One can rewrite (11) as follows

$$
\left(n^{2}-1\right)^{-1}=\frac{1}{S_{\mathrm{o}} \lambda_{\mathrm{o}}^{2}}-\frac{1}{S_{\mathrm{o}}} \frac{1}{\lambda^{2}},
$$

where $\lambda_{0}$ is the regular oscillator wavelength and $S_{\mathrm{o}}$ is the typical oscillator power. The variables $S_{\mathrm{o}}$ and $\lambda_{\mathrm{o}}$ in (12) can be estimated with the function $\left(n^{2}-1\right)^{-1}$ vs $\lambda^{2}$ and compare to the experimental points, as shown in Fig. 6. The variables $S_{\mathrm{o}}$ and $\lambda_{\mathrm{o}}$ in (12) can be estimated experimentally by the function $\left(n^{2}-1\right)^{-1}$ versus $\lambda^{2}$, as shown in Fig. 6 . The slope of the fitted straight line gives $1 / S_{0}$, and the endless capture of the wavelength gives $1 /\left(S_{0}\right) \times \lambda_{0}^{2}$. The evaluated values of $S_{0}$ and $\lambda_{0}$ are given in Table II.

\section{Conclusions}

Iron oxide $\mathrm{Fe}_{2} \mathrm{O}_{3}$ thin films of different thicknesses were deposited onto preheated glass substrates by SPT at the temperature of $450^{\circ} \mathrm{C}$. The diffraction pattern is polycrystalline, and the crystallization increases as film thickness increases. Noticable shifts occur in the value of the refractive index wavelength, from 2.42 to 2.91 , and the energy band gap which drops from $2.74 \mathrm{eV}$ to $2.21 \mathrm{eV}$. The Urbach energy values rise from 680 to 1230 and dispersal powers rise from 10.86 to 16.54 as the film thickness increases. The changes in these properties are important factors for consideration in potential areas of application of $\mathrm{Fe}_{2} \mathrm{O}_{3}$ thin films.

\section{Acknowledgments}

Authors would like to express their gratitude and acknowledge to the Department of Physics at College of Science of the Mustansiriyah University, Advanced Material Lab.

\section{References}

[1] M.F. Al-Kuhaili, M. Saleem, S.M.A. Durrani, J. Alloys Compd. 521, 178 (2012).

[2] M. Allen, D. Willits, J. Mosolf, M. Young, T. Douglas, Adv. Mater. 14, 1562 (2002).

[3] W.B. Ingler Jr., S.U.M. Khan, Thin Solid Films 461, 301 (2004).

[4] A.S. Hassanien, A.A. Akl, Appl. Phys. A 124, 752 (2018).

[5] B. Ouertani, J. Ouerfelli, M. Saadoun, H. Ezzaouia, B. Bessaïs, Thin Solid Films 516, 8584 (2008).

[6] H.G. Cha, C.W. Kim, Y.H. Kim, M.H. Jung, E.S. Ji, B.K. Das, J.C. Kim, Y.S. Kang, Thin Solid Films 517, 1853 (2009).

[7] J.M.G. Leal, Phys. Status Solidi B 250, 1044 (2013).

[8] A.A. El-Fadl, A.M. Al-Salam, A.M. Nashaat, Mater. Sci. Poland 36, 685 (2018).

[9] M. Fondell, T.J. Jacobsson, M. Boman, T. Edvinsson, J. Mater. Chem. A 2, 3352 (2014).

[10] Q.W. Chen, Y.T. Qian, H. Qian, Z.Y. Chen, W.B. Wu, Y.H. Zhang, Mater. Res. Bull. 30, 443 (1995).

[11] V. Goossens, J. Wielant, S.V. Gils, R. Finsy, H. Terryn, Surf. Interface Anal. 38, 489 (2006).

[12] A. Kumar, K. Yadav, Mater. Res. Express 4, 075003 (2017).

[13] C.M. Tian, W.-W. Li, Y.M. Lin et al., J. Phys. Chem. C 124, 12548 (2020).

[14] G. Neri, A. Bonavita, S. Galvagno, Y.X. Li, A. Trinchi, K. Galatsis, W. Wlodarski, Sens. Microsyst., 149 (2002).

[15] L. Francioso, S. Capone, P. Siciliano, D. Kotsikau, M. Ivanovskaya, Sens. Microsyst., 205 (2008). 